\title{
Gregory Feldman, The Migration Apparatus: Security, Labor, and Policymaking in the European Union
}

Stanford University Press, 2012, pp. 224

At a time in which the European Union is fortifying its borders in order to prevent "undesired" migrants from entering its territory, Gregory Feldman's book The Migration Apparatus: Security, Labor and Policymaking in the European Union, published by the Stanford University Press in 2012, is of invaluable importance for understanding the mechanisms governing EU policymaking on migration. In this book, Feldman maps EU migration policies and their development in the context of global economic inequality from an ethnographic point of view, using a Foucauldian approach.

The Foucauldian apparatus is a key concept in Feldman's work. This concept enables him to grasp the decentralized nature of EU migration policy, in which the actors involved are increasingly unrelated to each other. The apparatus furthermore contributes to making migration and migrants "manageable" through a variety of strategies. This also leads, according to Feldman, to the fact that migration policies are not the result of the morally best, but of the most practical approach. Moreover, the apparatus gains autonomy, which prevents individuals from counteracting it.

Feldman's aims are, firstly, to analyse the EU's migration apparatus within the global political and economic order, and secondly, to apply an adequate methodology to achieve this aim, something he terms "nonlocal ethnography". With these objectives, Feldman takes the reader on a journey through the world of EU policymaking. In the first chapter, he sets the scene of an increasingly disconnected and therefore merely mediated world. In the second chapter, Feldman identifies the sphere of EU migration policy as dominated by neoliberals and neonationalists, the former demanding a flexible workforce, the latter the protection of national interests. These two are, as Feldman argues, not different in kind but merely in degree. In the third chapter, Feldman describes strategies of unification and simplification as key mechanisms to achieve conformance within the apparatus. Having sketched the general workings of EU migration policies in the first three chapters, Feldman devotes the subsequent three chapters to specific EU policy fields: border control, biometrics, and circular migration. EU policies on border control are conceived by Feldman to be an attempt by the EU to harmonize its policies with the objective of keeping out "undesired" migrants from the Global South. While migration is treated as a mass phenomenon in this policy field, the migrants are highly individualized in the policies on biometrics. These policies, however, go hand in hand, since biometrics equally serve to distinguish between "desired" and "non-desired" migrants. According to Feldman, circular migration policies work as the "right solution", reconciling neoliberals and neonationalists, the entry of workers being allowed but limited to a specific time frame. In the final chapter, Feldman undertakes a methodological discussion, arguing for the use of nonlocal ethnography as a tool to map decentralized structures in a globalized world.

Having provided a brief summary of the book, four issues should be discussed more critically: the apparatus concept, the methodology of nonlocal ethnography, the supposed political divide, and the specificities of the EU.

Even though the use of the concept of the apparatus allows the conceptualization of the decentralized logic of EU migration policies, it methodologically excludes the agency of both policymakers and migrants in counteracting the migration apparatus. The denial 
of the agency of migrants is also an effect of the framework in which Feldman places migration, namely in the context of globally economic inequality. Even though these global inequalities must be acknowledged, poverty-related reasons are not the only causes of migration, as Feldman's analysis might sometimes lead us to believe.

Closely linked to the discussion of the apparatus as the key concept of this book is the discussion of the methodology of nonlocal ethnography. The author attempts to use this methodology to overcome the difficulty of mapping decentralized phenomena and thereby provide a methodological equivalent to the apparatus concept. The underlying logic of the methodology is that neither core locations for ethnographic study exist nor should the mere interconnectedness of sites be studied, the rationales and practices being "present in multiple locations but are not of any particular location".

On the one hand, nonlocal ethnography does provide an answer to the problematic of doing ethnography in a globalized world. On the other hand, the necessity of choosing loci for the research, be they virtual or real, cannot be circumvented. In the case of Feldman's study, one of his main claims, namely that EU policymaking follows a technocratic logic, is undermined by his choice of loci. Even though the descriptions and analyses of the various conferences and meetings are very insightful, the sites appear to be quite homogeneous, in the sense that none of them is a political space. His argument that migration policy tends to be technocratic would be more compelling if he could show his readers that this logic is also present at the core of the EU's political institutions. An analysis of more political spaces would also either reinforce or contradict his claim that EU migration policy is dominated by the neoliberal and the neonationalist right. An alternative explanation would be the makeup of the EU as a structure which is highly influenced by national interests.

In the same line of argument, the EU's circular migration policies are portrayed to be the perfect compromise between neoliberals and neonationalists. Feldman's reasoning that neoliberals and neonationalists would both see their claims fulfilled, the first pushing for a mobile workforce, and the latter for a restriction of the migrants' stay in their respective countries, is convincing. Nevertheless, one might ask whether these policies do not also partially fulfil the claims of the moderate left - which Feldman supposes to be non-existent - since circular migration schemes provide possibilities, at least for some migrants, to come to Europe. Even though these schemes might follow a neoliberal rationale and might, as Feldman warns, be used to obfuscate structural sources of inequality, a closer examination of circular migration schemes should be undertaken in order to avoid the risk of discarding them too rapidly.

One of the book's general underlying arguments is that the communautarization of migration policies in the EU has led to harsher rules concerning immigration processes. However, a comparison with the pre-Schengen situation is misleading, since information technologies allowing for enhanced control of borders and the collection of biometric data have continued to develop since the implementation of the Schengen Area. No explicit argument is given as to why individual nation-states would not have adopted similar policies. The choice of policy areas for the analysis of this book also receives no further justification. It would have been interesting, for instance, to see whether the same logic governs EU asylum policies, which are not addressed in this book. Even though asylum is a very restricted policy field, the EU being very far from having a common asylum policy, the adopted policies have led to some legal improvements in some of the Member States, most notably in form of the Qualification and the Reception Directives. 
In summary, the main weaknesses of the book are the limitations of the findings relating to the utility of the apparatus concept and some open questions regarding the methodology of nonlocal ethnography, the specific institutional characteristics of the EU and the supposed divide in the political sphere. In spite of this, one can say that the book delivers what it promises to deliver in the introduction. First, Feldman succeeds in analysing the decentralized field of EU migration politics in a globally unequal world order. He argues in a well-structured and convincing way how the various domains of migration policy are part of the migration apparatus, which produces a specific subject position for migrants and "functions to maintain a large-scale apartheid between the North and South precisely because the prosperity of the former cannot be universalized to include the latter". Second, Feldman successfully opens up new perspectives for ethnographic research in a globalized world, thereby contributing to the debate on how ethnography is well-suited to respond to globalization, as discussed since the 1980s.

Laura Boucsein 